\title{
The role of demographic and clinical variables in assessing the quality of life of outpatients with rheumatoid arthritis
}

\author{
Grażyna Bączyk, Katarzyna Kozłowska
}

Department of Nursing Practice, Faculty of Health Sciences, Poznan University of Medical Sciences, Poznan, Poland

Submitted: 4 December 2016

Accepted: 6 April 2017

Arch Med Sci 2018; 14, 5: 1070-1079

DOI: https://doi.org/10.5114/aoms.2018.77254

Copyright $\odot 2018$ Termedia \& Banach

\section{Abstract}

Introduction: The aim of this study was to assess quality of life among patients with rheumatoid arthritis (RA) treated as outpatients. The specific question was: does the quality of life of RA patients depend on demographic variables and clinical variables?

Material and methods: The study included 240 patients with RA recruited from outpatients. To assess quality of life, the Arthritis Impact Measurement Scales 2 was applied. Clinical tests: VAS, Morning Stiffness, Grip Strength, Richie Articular Index.

Results: The analysis of life quality for the total group was carried out in the particular AIMS2 of the mean scores for arthritis pain - 7.37; walking and bending -6.62 ; social activity -5.52 ; level of tension -5.17 ; satisfaction - 5.17; hand and finger function - 4.28; mood - 4.03; physical activity - 3.27; arm function - 3.16; household tasks - 2.67; self-care -2.18 ; and support from family and friends -1.75 . The arthritis impact score was 6.01 . The analysis of the correlation between clinical variables and individual AIMS2 subscales showed a statistically significant relationship between the VAS Pain, Grip Strength Measurement, Morning Stiffness and quality of life subscales $(p<0.01)$. VAS Pain, Morning Stiffness, and Grip Strength Measurement were the most important predictors among clinical variables of physical component, affect and symptoms $(p<0.001)$. Among demographic variables: age over 60 years and low education were the most important predictors of physical component $(p<0.01)$.

Conclusions: The study results may be helpful for further health-related studies on quality of life among RA studies and in making therapeutic decisions concerning quality of life improvement.

Key words: quality of life, RA patients, outpatients, Arthritis Impact Measurement Scales 2.

\section{Introduction}

Rheumatoid arthritis (RA) is a chronic progressive inflammatory connective tissue disease leading to the destruction of articular and periarticular tissues, thus causing distortion and dysfunction of these tissues, and resulting in the permanent disability of the patient. Additionally, coexisting diseases and frequent complications caused by inappropriate treatment also cause a loss of functional efficiency. The evaluation of quality of life $(\mathrm{QOL})$ among patients with rheumatoid arthritis refers to

\author{
Corresponding author: \\ Grażyna Bączyk PhD \\ Department of \\ Nursing Practice \\ Faculty of \\ Health Sciences \\ Poznan University \\ of Medical Sciences \\ 11 Smoluchowskiego St \\ 60-179 Poznan, Poland \\ Phone: +48 61692562364 , \\ +48616559261 \\ Fax: +48616559266 \\ E-mail: gbaczyk@ump.edu.pl
}


such aspects as the physical, the emotional, and the social, arthritic pain, and their influence on patients' functioning. The effect of RA on quality of life in the physical aspect refers to arthritic pain intensity which aggravates patients' everyday activities. The support of family and friends and appropriate treatment are important factors for the proper functioning of RA patients. The main aim of health care for such patients with joint disorders is to maintain their self-care and preserve a decent quality of life [1-3].

According to the WHO, the concept of Health-Related Quality of Life (HRQoL) concerns functioning in basic key areas: physical, mental and social as well as subjective evaluation of the patient $[4,5]$.

This idea includes both objective and subjective dimensions and is usually used in the evaluation of treatment and research. The tools used to measure quality of life can be divided into the general (called global scales), the non-specific (called generic scales) and the specific (called disease-specific scales), depending on the structure. General scales relate to the general definition and enable the measurement of the overall quality of life and/ or other tested areas. Non-specific scales are the most versatile and they allow the comparison of different groups of patients and healthy persons. They include most of the postulated dimensions that make up quality of life. Moreover, they focus on the specific problems of specific groups of patients. They usually require more time for assessing the changes because they involve deeper areas of dysfunction that change more slowly [6].

Specific scales assess a narrower range than the non-specific tools and they are used to assess the quality of life of patients with a particular disease, as they usually have a higher sensitivity to changes [6-8].

According to the literature review on the quality of life in patients with RA, the most commonly used scale is the Arthritis Impact Measurement Scales based on the idea that quality of life is determined by health [9-12]. The above scale allows the evaluation of the influence of disease on patients' functioning with regard to the physical, psychological and social aspects as well as in somatic sensations.

The aim of this study was to assess quality of life among patients with RA treated in the Rheumatoid Outpatient Clinic in Poznan, Poland. The specific question was: does the quality of life of RA patients depend on demographic variables (gender, age, education, marital status) and clinical variables (disease duration, pain, morning stiffness, grip strength, tenderness of joints)?

\section{Material and methods}

The study included 240 patients with RA recruited from outpatients in the Rheumatoid Out- patient Clinic in Poznan, Poland. The major inclusion criterion was RA diagnosed according to the American College of Rheumatology (ACR) criteria (formerly the American Rheumatism Association) [13] and the European League Against Rheumatism (EULAR) [14]. Exclusion criteria for the group included severe neurological disorders and other different illness, the presence of which could influence the assessment of quality of life.

The study group consisted of 180 women and 60 men (mean age: $52.15 \pm 12.73$ years). All patients were interviewed to collect data on the following clinical and socio-demographic parameters: age, marital status, school education, job and workplace, use of anti-inflammatory drugs, steroids, methotrexate or leflunomide or other drugs.

Next, the clinical parameters were measured. Afterwards, the subjects completed the questionnaire alone in a separate room and we checked whether all the questions had been answered.

The quality of life was assessed using the Polish version of the Arthritis Impact Measurement Scales 2 (AIMS2) self-administered among all patients and 90 age-and sex-matched healthy subjects as the control group (20 hospital employees, 40 university employees, and 30 employee relatives). The mean age of the control group was $54.76 \pm 9.65$ years.

The AIMS2 by Meenan et al. [15] was adapted to Polish conditions by Bączyk et al. [16]. The reliability of the Polish questionnaire was assessed by the internal consistency of health-status scales. Construct validity was assessed by factor analysis and convergent validity by correlation coefficients with disease activity variables and duration of disease. Internal consistency was $0.79-0.89$. The AIMS2 is a 78-item questionnaire. The first 57 items were broken down into 12 scales: 1 - mobility level, 2 walking and bending, 3 - hand and finger function, 4-arm function, 5 - self-care tasks, 6 - household tasks, 7 - social activity, 8 - support from family and friends, 9 - pain from arthritis, 10 - work, 11 level of tension 12 - mood. The number of items in each scale was either 4 or 5 .

Item 58 concerns the respondents' satisfaction with each of the 12 scales. Item 59 asks the respondents to report how many of their problems with any of these 12 scales are attributable to RA. Item 60 asks the patient to prioritise the 3 areas in which the patient would most like to see improvement. The next items assessed the overall impact of RA. The AIMS2 scales could be combined into 5 component models: physical, affect, symptom, social interaction, role. The AIMS2 scores range from 0 to 10 , with 0 representing a high quality of life and 10 representing a poor quality of life. The subjects completed the questionnaire alone 
in a separate room and we checked whether all questions had been answered.

\section{Clinical tests}

The Visual Analogue Scale (10 cm Pain VAS): The standard visual analogue scale is a $10 \mathrm{~cm}$ scale with a border on each side. To the left of the " 0 " mark appear the words "no pain" and to the right of the "10" mark appear the words "the worst possible pain" [17]. The study also evaluated Morning Stiffness (duration of morning stiffness in minutes from waking up until maximal improvement, with a maximum of $300 \mathrm{~min}$ ), Grip Strength (measured by a vigour meter) and tenderness of joints (by the Ritchie Articular Index). According to the Richie Articular Index, the joints are graded for tenderness on a 0-3 scale, with 3 being maximal tenderness: 0 - no tenderness; 1 - pain on pressure; 2 - pain and winced; 3 winced and withdrew (maximum score: 78) [18].
The study was approved by the Research Ethical Committee at the Poznań University of Medical Sciences.

\section{Statistical analysis}

Descriptive statistics of all the variables are presented as percentages and mean and standard deviation (SD). Comparisons between groups were performed using the Mann-Whitney U-test and Kruskal-Wallis test. Spearman's correlation was used to assess the relationships between the AIMS2 score and clinical variables.

In order to determine the role of demographic and clinical variables in the assessment of quality of life, a stepwise logistic regression analysis and Akaike Information Criterion (AIC) for model assessment were performed. The cut-off for the AIMS-2 scale was set at the median for each area. Scores equal to the median or lower indicated high QOL, while scores higher than the median indicated low QOL.

Table I. Demographic and clinical characteristics of patients with RA and control group

\begin{tabular}{|c|c|c|c|}
\hline Variables & $\begin{array}{l}\text { RA patients } \\
(n=240)\end{array}$ & $\begin{array}{l}\text { Control group } \\
(n=90)\end{array}$ & $P$-value \\
\hline Age, mean \pm SD [years] & $52.15 \pm 12.73$ & $54.76 \pm 9.65$ & NS \\
\hline$\leq 39, n(\%)$ & $58(24.2)$ & $28(31.1)$ & \\
\hline $40-60, n(\%)$ & $102(42.5)$ & $32(35.6)$ & \\
\hline$>60, n(\%)$ & $80(33.3)$ & $30(33.3)$ & \\
\hline Female, $n(\%)$ & $180(75)$ & $65(72.2)$ & NS \\
\hline Male, $n(\%)$ & $60(25)$ & $25(27.8)$ & \\
\hline \multicolumn{4}{|l|}{ Marital status, $n(\%)$ : } \\
\hline Married & $188(78.3)$ & $69(76.7)$ & \\
\hline Single & $52(21.7)$ & $21(23.3)$ & NS \\
\hline Education, $n(\%)$ : & & & 0.02 \\
\hline Primary & $56(23.4)$ & & \\
\hline Secondary vocational & $82(34.2)$ & $8(8.9)$ & \\
\hline Secondary & $80(33.3)$ & $20(22.2)$ & \\
\hline University-level & $22(9.10)$ & $28(31.1)$ & \\
\hline Paid work, $n(\%)$ : & $56(23.4)$ & $34(37.8)$ & 0.04 \\
\hline RA duration, mean \pm SD [years] & $13.7 \pm 8.62$ & & \\
\hline VAS Pain $(0-10 \mathrm{~cm})$, mean \pm SD & $6.16 \pm 1.76$ & & \\
\hline Morning Stiffness (min.), mean \pm SD & $103 \pm 0.93$ & & \\
\hline Grip Strength Measurement (right), mean $\pm \mathrm{SD}[\mathrm{mm} \mathrm{Hg}]$ & $80.0 \pm 46.71$ & & \\
\hline Grip Strength Measurement (left), mean \pm SD [mm Hg] & $76.15 \pm 47.1$ & & \\
\hline Ritchie Articular Index, mean \pm SD & $21.56 \pm 11.1$ & & \\
\hline
\end{tabular}

RA - rheumatoid arthritis, VAS - visual analogue scale, Ritchie Articular Index - 3 being maximal tenderness: 0 - no tenderness, 1 - pain on pressure, 2 - pain and winced, 3 - winced and withdrew. 
The regression analysis model used all variables with a potential impact on QOL as predictors. The following were quantitative continuous variables: age, $10 \mathrm{~cm}$ Pain VAS, Morning Stiffness, Grip Strength, tenderness of joints, RA duration.

The other variables were considered as categorical (0-1): gender, education and work status. $P<0.05$ was accepted as the level of statistical significance.

Statistical analysis was performed using SPSS for Windows Version 20 (SPSS Inc., Chicago, IL, USA).

\section{Results}

\section{Socio-demographic and clinical results}

The total study sample consisted of 240 individuals. The clinical and demographic characteristics of patients and the healthy controls are listed in Table I.

Most of them were married (78.3\%). Most of the respondents were disability pensioners or else retirees $(76.6 \%)$ (Table I). All of the patients received anti-inflammatory drugs, $25.8 \%$ received steroids and $18.7 \%$ of respondents received steroids together with methotrexate and $2.5 \%$ of patients received leflunomide. Patients did not receive a human anti-TNF monoclonal antibody or other biological drugs. Fifty-eight percent of the group had no co-morbidities, $35 \%$ had hypertension and $7 \%$ had another medical condition. All of the patients were qualified to the secondary/third period of the disease according to Steinbrocker's criteria [19].

The results showed the mean scores for clinical tests as: $10 \mathrm{~cm}$ pain VAS: $6.16 \pm 1.76 \mathrm{~cm}$; Morning stiffness: $103 \pm 0.93 \mathrm{~min}$; Grip Strength Measurement right hand: $80 \pm 46.71 \mathrm{~mm} \mathrm{Hg}$; Measurement of left hand: $76.15 \pm 47.14 \mathrm{~mm} \mathrm{Hg}$; Ritchie Articular Index: $21.56 \pm 11.1$ points. Values: Grip Strength Measurement of right hand and Grip Measurement of left hand in men were significantly higher than in women. There was no statistically significant difference in other measurements. The mean duration of RA for the whole group was $13.7 \pm 8.62$ years (Table I).

\section{Quality of life of patients with RA}

The quality of life of patients with rheumatoid arthritis was determined by analysing the mean scores in each of the subscales of the AIMS2 scale.

The analysis of life quality for the RA patients was carried out in the particular AIMS2 of the mean scores for arthritis pain - 7.37; walking and bending - 6.62; social activity - 5.52; level of tension - 5.17; satisfaction - 5.17; hand and finger function - 4.28; mood - 4.03; arm function - 3.68; household task - 3.57; self-care - 2.89; and support from family and friends -1.75 . The arthritis impact score was 7.63. The patients with RA had significantly higher scores in all subscales com-

Table II. Mean scores of RA patients and control group for AIMS 2 subscales (mean \pm SD)

\begin{tabular}{|lccc|}
\hline AIMS-2 subscales & $\begin{array}{c}\text { RA patients } \\
(n=240)\end{array}$ & $\begin{array}{c}\text { Controls } \\
(n=90)\end{array}$ & $P$-value \\
\hline Mobility level & $3.97 \pm 2.19$ & $0.79 \pm 0.54$ & $<0.0001$ \\
\hline Walking and bending & $6.62 \pm 2.2$ & $1.54 \pm 0.71$ & $<0.0001$ \\
\hline Hand and finger function & $4.28 \pm 2.58$ & $0.67 \pm 0.43$ & $<0.0001$ \\
\hline Arm function & $3.68 \pm 2.07$ & $0.37 \pm 0.13$ & $<0.0001$ \\
\hline Self-care & $2.89 \pm 2.66$ & $0.17 \pm 0.37$ & $<0.0001$ \\
\hline Household tasks & $3.57 \pm 2.56$ & $0.14 \pm 0.60$ & $<0.001$ \\
\hline Social activities & $5.52 \pm 1.9$ & $2.18 \pm 1.60$ & 0.932 \\
\hline Support from family & $1.75 \pm 2.1$ & $1.25 \pm 1.80$ & $<0.0001$ \\
\hline Arthritis pain & $7.37 \pm 1.84$ & - & $<0.001$ \\
\hline Work & $5.59 \pm 2.47$ & $0.55 \pm 0.96$ & $<0.001$ \\
\hline Level of tension & $5.17 \pm 1.34$ & $4.95 \pm 1.89$ & $<0.001$ \\
\hline Mood & $4.03 \pm 1.49$ & $2.56 \pm 1.51$ & $<0.001$ \\
\hline Satisfaction & $5.17 \pm 1.83$ & $2.45 \pm 1.45$ & - \\
\hline Health perception & $5.17 \pm 1.83$ & $3.98 \pm 2.12$ & \\
\hline Arthritis impact & $7.63 \pm 2.46$ & & \\
\hline Score range 0-10; $0-$ high quality of life, 10 - poor quality of life. & & & \\
\hline
\end{tabular}


pared to the healthy control group except support from family (Table II).

The first analysis was used to evaluate the quality of life of patients with rheumatoid arthritis and to identify whether there is a statistically significant difference between the quality of life of women and men (Table III).

Women obtained higher mean values in each component. Statistically significantly higher mean values for women were found in the physical component and the affect.

Next, the effect of age on the quality of life of respondents was evaluated. Therefore, the respondents were divided into three age groups: $\leq 39$ years old, $40-59$ years and $\geq 60$ years old. The mean values were higher for elderly patients for most AIMS2 components. The Kruskal-Wallis test showed a statistically significant difference in quality of life for the physical component for respondents aged $\leq 39$ years and $\geq 60$ years. Young- er patients evaluated their quality of life higher in the component than did respondents aged $\geq 60$ years. There were no significant differences in the quality of life of the respondents in other age categories.

Education was the next variable analysed as affecting the quality of life of respondents.

Statistically significant differences were found in the physical component and affect.

Respondents with lower education levels obtained higher mean scores in the above components. In the affect component, respondents with university-level education obtained lower scores than patients with secondary-level, vocational-secondary and primary-level education. There were no statistically significant differences in scores according to marital status and duration of disease for AIMS 2 components (Table III).

The analysis of the correlation between clinical variables and individual AIMS2 subscales

Table III. Comparison of means between AIMS2 components and demographic parameters and disease duration in RA patients $(n=240)$

\begin{tabular}{|c|c|c|c|c|c|}
\hline Parameter & $\begin{array}{l}\text { Physical } \\
\text { Mean } \pm \text { SD } \\
\text { (p-value) }\end{array}$ & $\begin{array}{l}\text { Social inter- } \\
\text { action } \\
\text { Mean } \pm \text { SD } \\
(p \text {-value })\end{array}$ & $\begin{array}{c}\text { Affect } \\
\text { Mean } \pm \text { SD } \\
\text { (p-value) }\end{array}$ & $\begin{array}{c}\text { Symptoms } \\
\text { Mean } \pm \text { SD } \\
\text { (p-value) }\end{array}$ & $\begin{array}{c}\text { Role } \\
\text { Mean } \pm \text { SD } \\
(p \text {-value })\end{array}$ \\
\hline \multicolumn{6}{|l|}{ Gender: } \\
\hline Women & $4.28 \pm 2.58$ & $5.97 \pm 1.81$ & $5.36 \pm 1.18$ & $7.25 \pm 1.18$ & $5.68 \pm 2.39$ \\
\hline Men & $\begin{array}{c}3.28 \pm 3.07 \\
(0.04)\end{array}$ & $\begin{array}{c}5.36 \pm 2.12 \\
(0.12)\end{array}$ & $\begin{array}{c}4.60 \pm 1.62 \\
(0.02)\end{array}$ & $\begin{array}{c}6.55 \pm 1.62 \\
(0.16)\end{array}$ & $\begin{array}{c}5.27 \pm 2.84 \\
(0.25)\end{array}$ \\
\hline \multicolumn{6}{|l|}{ Age: } \\
\hline$(1) \leq 39$ & $3.11 \pm 2.19$ & $5.22 \pm 1.29$ & $5.17 \pm 1.44$ & $6.5 \pm 1.88$ & $5.83 \pm 2.18$ \\
\hline (2) $40-59$ & $3.42 \pm 2.77$ & $5.57 \pm 2.8$ & $5.16 \pm 1.98$ & $7.12 \pm 1.91$ & $5.55 \pm 2.47$ \\
\hline (3) $\geq 260$ & $\begin{array}{c}4.76 \pm 3.89 \\
(0.02) \\
(1: 3)\end{array}$ & $\begin{array}{c}5.91 \pm 2.62 \\
(0.43)\end{array}$ & $\begin{array}{c}5.16 \pm 1.98 \\
(0.26)\end{array}$ & $\begin{array}{c}7.34 \pm 1.64 \\
(0.31)\end{array}$ & $\begin{array}{c}5.37 \pm 3.38 \\
(0.28)\end{array}$ \\
\hline \multicolumn{6}{|l|}{ Education: } \\
\hline (1) Primary & $4.01 \pm 1.86$ & $5.19 \pm 1.9$ & $5.2 \pm 2.54$ & $6.91 \pm 2.6$ & $5.61 \pm 2.34$ \\
\hline (2) Secondary vocational & $4.05 \pm 1.56$ & $5.56 \pm 2.34$ & $5.32 \pm 2.12$ & $7.13 \pm 2.45$ & $5.43 \pm 2.76$ \\
\hline (3) Secondary & $3.12 \pm 1.71$ & $5.45 \pm 2.16$ & $5.25 \pm 2.89$ & $7.08 \pm 1.89$ & $5.3 \pm 2.23$ \\
\hline (4) University-level & $\begin{array}{c}3.22 \pm 1.74 \\
(0.01) \\
(1,2: 3,4)\end{array}$ & $\begin{array}{c}5.51 \pm 2.09 \\
(0.34)\end{array}$ & $\begin{array}{c}4.31 \pm 1.69 \\
(0.03) \\
(1,2,3: 4)\end{array}$ & $\begin{array}{c}7.12 \pm 2.13 \\
(0.42)\end{array}$ & $\begin{array}{c}5.7 \pm 2.56 \\
(0.37)\end{array}$ \\
\hline \multicolumn{6}{|l|}{ Marital status: } \\
\hline Married & $3.30 \pm 2.29$ & $3.28 \pm 2.02$ & $4.12 \pm 1.41$ & $6.13 \pm 2.05$ & $5.65 \pm 2.71$ \\
\hline Single & $\begin{array}{c}3.16 \pm 1.89 \\
(0.31)\end{array}$ & $\begin{array}{c}2.90 \pm 2.20 \\
(0.23)\end{array}$ & $\begin{array}{c}3.76 \pm 1.58 \\
(0.34)\end{array}$ & $\begin{array}{c}5.70 \pm 2.6 \\
(0.38)\end{array}$ & $\begin{array}{c}5.23 \pm 2.35 \\
(0.42)\end{array}$ \\
\hline \multicolumn{6}{|l|}{ Disease duration } \\
\hline$\leq 5$ years & $3.38 \pm 2.69$ & $3.28 \pm 2.89$ & $4.42 \pm 2.48$ & $5.63 \pm 2.15$ & $5.35 \pm 2.51$ \\
\hline$>5$ years & $\begin{array}{c}3.46 \pm 1.19 \\
(0.51)\end{array}$ & $\begin{array}{c}3.49 \pm 2.76 \\
(0.33)\end{array}$ & $\begin{array}{c}3.96 \pm 2.55 \\
(0.44)\end{array}$ & $\begin{array}{c}5.30 \pm 2.68 \\
(0.52)\end{array}$ & $\begin{array}{c}5.63 \pm 2.25 \\
(0.48)\end{array}$ \\
\hline
\end{tabular}


Table IV. Correlation between AIMS2 subscales and clinical parameters in RA patients

\begin{tabular}{|c|c|c|c|c|}
\hline AIMS2 subscales & VAS Pain $(0-10 \mathrm{~cm})$ & $\begin{array}{l}\text { Morning Stiffness } \\
\text { [min] }\end{array}$ & $\begin{array}{l}\text { Grip Strength } \\
\text { Measurement } \\
{[\mathrm{mm} \mathrm{Hg}]}\end{array}$ & $\begin{array}{l}\text { Ritchie Articular } \\
\text { Index }\end{array}$ \\
\hline Mobility level & $0.128^{*}$ & $0.116^{*}$ & $-0.141^{*}$ & 0.034 \\
\hline Walking and bending & $0.108^{*}$ & $0.108^{*}$ & $-0.26^{\star}$ & 0.054 \\
\hline Hand and finger function & $0.115^{*}$ & 0.076 & $-0.321^{\star \star}$ & 0.044 \\
\hline Arm function & $0.109^{*}$ & 0.037 & $-0.108^{\star}$ & 0.023 \\
\hline Self-care & $0.214^{*}$ & $0.103^{*}$ & $-0.168^{\star}$ & 0.015 \\
\hline Household tasks & $0.205^{*}$ & $0.104^{*}$ & $-0.171^{\star}$ & 0.027 \\
\hline Social activities & $0.216^{*}$ & 0.061 & $-0.127^{\star}$ & 0.035 \\
\hline Support from family & 0.011 & -0.038 & $-0.146^{\star}$ & 0.017 \\
\hline Arthritis pain & $0.215^{*}$ & 0.060 & $-0.283^{\star *}$ & 0.014 \\
\hline Work & $-0.133^{*}$ & $-0.113^{*}$ & $-0.224^{\star \star}$ & 0.065 \\
\hline Level of tension & 0.094 & $0.116^{*}$ & $-0.164^{*}$ & 0.045 \\
\hline Mood & 0.095 & 0.081 & $-0.146^{*}$ & 0.081 \\
\hline Satisfaction & $0.165^{*}$ & 0.065 & $-0.176^{\star}$ & 0.076 \\
\hline Health perception & $0.187^{\star}$ & $0.157^{*}$ & $-0.162^{*}$ & 0.068 \\
\hline Arthritis impact & $0.134^{*}$ & $0.184^{*}$ & $-0.174^{\star}$ & 0.054 \\
\hline
\end{tabular}

showed a statistically significant relationship between the VAS Pain, Grip Strength Measurement, Morning Stiffness and quality of life subscales. The strongest correlation was found between Grip Strength Measurement and arthritis pain, work, hand and finger function. Moreover, a strong correlation for satisfaction was found. There was no statistically significant correlation between the Ritchie Articular Index and the subscales (Table IV).

Table $V$ shows the factors associated with QOL for RA patients by logistic regression analysis. Regression analysis showed that VAS Pain, Morning Stiffness, and Grip Strength Measurement were the most important predictors of physical component, affect and symptoms $(p<0.001)$.

Table V. Variables associated with AIMS2 components in RA patients evaluated by stepwise multiple logistics regression analysis

\begin{tabular}{|lcccc|}
\hline Component & Variables & $P$-value & OR & $95 \% \mathrm{Cl}$ \\
\hline Physical & Age $(\geq 60$ years old $)$ & 0.01 & 1.39 & $1.25-1.63$ \\
\cline { 2 - 5 } & Primary and secondary vocational education & 0.04 & 1.24 & $1.04-1.84$ \\
\cline { 2 - 5 } & VAS pain & 0.001 & 2.02 & $1.35-3.04$ \\
\cline { 2 - 5 } & Morning Stiffness & 0.001 & 2.22 & $1.32-3.34$ \\
\hline Social interaction & Grip Strength Measurement & 0.001 & 1.18 & $1.08-1.33$ \\
\hline Affect & VAS pain & 0.001 & 1.76 & $1.32-2.71$ \\
\cline { 2 - 5 } & Wrimary and secondary vocational education & 0.004 & 1.49 & $1.29-1.82$ \\
\cline { 2 - 5 } & Grip Strength Measurement & 0.02 & 2.48 & $1.13-5.39$ \\
\hline Symptoms & VAS pain & 0.001 & 2.52 & $1.09-5.82$ \\
\hline Role & Grip Strength Measurement & 0.02 & 2.3 & $1.30-5.14$ \\
\hline
\end{tabular}

$O R$ - odds ratio, $\mathrm{Cl}$ - confidence interval. 


\section{Discussion}

Our research shows that a good assessment of quality of life among RA patients depended on the support received from family and friends (expressed by the mean value 1.75). The poor assessment of the quality of life of RA patients was due to their limited ability to perform the basic activities of life. This was associated with arthritis pain (mean score: 7.37 ) and walking and bending (mean score: 6.62).

The evaluation of quality of life in patients with RA using the AIMS2 scale has been carried out through many studies and among patients of different nationalities. Hill et al. [9] assessed the quality of life in RA patients in the English population. Based on a three-component AIMS scale, the mean values for physical functioning, mobility and emotional functioning were average, but the joint pain intensity was high. The results of the assessment of quality of life in the subscale of physical functioning, mobility and joint pain correlated with the outcome of the physical functioning Health Assessment Questionnaire (HAQ) scale. Meenan et al. [15] compared the quality of life of patients with RA with patients with osteoarthritis. The quality of life of patients with osteoarthritis was better in the subscale of self-care and in the social activity subscale compared with the quality of life of patients with RA. Worse quality of life was found in the hand and finger activity areas and for activities involving the shoulder joint in RA patients.

Using the Spanish version of the AIMS, Abello-Banfi and Cardie [10] evaluated the quality of patients with RA treated in a rheumatological outpatients' clinic. Quality of life was assessed as average in the everyday activities subscale and the physical functioning, social activities and emotional functioning subscales.

Seventy-eight patients treated in the rheumatological outpatients clinic participated in the longterm Archenholtz and Bjelle research [11]. The average quality of life was found in the following subscales: physical activity, self-care activities, everyday living activities, family and friends' support, work, level of emotional tension and mood. Poor quality of life was found in such subscales as hand and finger activity, walking and bending, joint pain and social activity. The research conducted by the Polish scientist Bączyk et al. [12] showed that the overall assessment of quality of life of patients with RA has the average value. Poor quality of life of patients with RA was due to the limited possibilities surrounding basic life activities. This was associated with joint pain, difficulties in walking and bending as well as with increased emotional tension and a tendency to depression. In another study, Bączyk et al. [20] compared the quality of life of patients with RA and patients with osteo- arthritis. No significant difference in quality of life was found in the researched groups, although the average values in specific areas of the AIMS2 scale were lower (better quality of life) in patients with RA. It was found, however, that patients with RA evaluated their health status significantly higher than patients with osteoarthritis.

Research carried out by Sierakowska et al. [21] aimed to assess the quality of life of patients with RA according to the following aspects: physical, psychological, social and environmental relationships using the WHOQOL BREF questionnaire. It was found that patients scored worse in the physical area (activities of daily living, dependency on treatment, energy and fatigue, mobility and pain) and in the environmental area (across the range of freedom, mental security, availability and quality of care). According to the reports of Sierakowska, two-thirds of respondents were dissatisfied with their health.

\section{Quality of life and socio-demographic factors}

Socio-demographic factors may affect the quality of functioning in various areas of life, such as age, sex, marital status, place of residence and level of education. In elderly RA patients, the disease accelerates physical dependence on the environment and psychosocial disability as well as reducing the performance of daily tasks. Our research shows that women scored lower in the emotional aspects than men. The age of the respondents influenced the assessment of the quality of life of RA patients. Young patients scored higher in the physical functioning mobility subscales. Life satisfaction and quality of life in the emotional subscales were scored higher in patients with rheumatoid arthritis and with secondary-level and university-level education. A study concerning the impact of RA on physical fitness in relation to sex was carried out in Britain. All of the group was qualified to the third period of the disease, according to Steinbrocker's classification. Women had worse outcomes in terms of dress, taking care of their appearance, eating, walking, reaching and grasping. These results suggested that RA had a greater influence on quality of life in women than men [9].

Meenan et al. [15] applied the AIMS2 scale to assess quality of life in patients with RA who were ill for longer than 5 years in terms of such socio-demographic variables as gender, age, marital status and level of education. The obtained values evaluating quality of life for the physical activity subscale were low. In all other AIMS2 subscales respondents obtained average values. It was concluded that quality of life in the emotional functioning subscale increases with age, whereas sex, marital status and educational level did not cor- 
relate with the quality of life of AIMS2 subscales. Additionally, the authors of the study claimed that in patients with the disease lasting longer than 5 years the quality of life was stable. Physical disability progressed rapidly in the early stages of the disease and the process was very slow in the succeeding years. Our research in contrast did not show an association with disease duration and quality of life.

The research of Meenan et al. [15] showed no correlation between the level of education and disability. The results differ from the results of Pincus and Callahan [22], who found that in patients with a low level of education, the course of RA is more severe. The connections between learning and the development of RA are unknown. Education as an indicator of patient behaviour may result in better health habits by actively participating in the therapeutic process (adherence). One of the studies concluded that $65 \%$ of patients could not specify the type of their rheumatic disease. This fact is closely connected with a low level of education [22]. Similar results can be observed in the Gamal et al. [23] study, which showed that higher education levels were associated with better QOL scores. In our study, in the affect component, respondents with university-level education obtained lower scores than patients with secondary-level, vocational-secondary and primary-level education.

On the other hand, Sierakowska et al. [21] found that a long duration of RA gradually decreases quality of life, especially in the physical area, with rural residents being better assessed in terms of their physical functioning when compared with urban residents, and single patients evaluating their quality of life as being much lower than married patients.

According to the results of the Gamal et al. [23] study, disease duration was the most important independent predicting factor, being related to impairment of both physical and mental components of QOL. Similarly, Haroon et al. [24] observed a significant effect of duration of disease, functional disability and disease activity on QOL, with functional disability having the greatest strength of association.

\section{Quality of life and clinical variables}

In the research analysing the impact of clinical factors on quality of life of patients with RA in specific aspects, joint pain intensity (measured by the VAS scale), tenderness of joints (the Ritchie Articular Index and the Thompson Index), hand muscle strength (based on hand grip strength), the symptom of morning stiffness, haemoglobin, the erythrocyte sedimentation rate (ESR) value and the concentration of acute phase proteins were all measured. Our research shows that the assessment of quality of life in patients with rheumatoid arthritis in most of the subscales correlated with their hand muscle strength, a symptom of morning stiffness and joint pain intensity.

Carrying out research on a group of women with RA treated in an outpatient rheumatological clinic, Nordenskiold and Grimby [25] found a strong correlation between muscle strength of the right and left hand and joint pain intensity and the ability to perform daily living activities. Eight out of 20 tasks in the Health Assessment Questionnaire were highly correlated with hand muscle strength; $65 \%$ of the women studied avoided such tasks as vacuuming, bathing in the bathtub and activities requiring hand muscle strength (e.g., opening jars), and tasks requiring activity of the hand interphalangeal joints (such as fastening buttons and tying shoelaces). The above tasks required the involvement of working joints (i.e. hip, knee, shoulder and elbow joints).

Fitzpatrick [26] assessed the quality of functioning of patients with RA using the Nottingham Health Profile (NHP) and the AIMS. They used the following clinical tests: the Ritchie Articular Index (to assess joint tenderness and hand muscle strength) and the $10 \mathrm{~cm}$ VAS Pain (to measure the pain intensity of joints and the duration of morning stiffness). $34.2 \%$ of the study group consisted of patients hospitalised after an accident, with the other patients being treated in the rheumatological outpatient clinic. According to the classification criteria of functional status in RA, 6.8\% of respondents were able to completely carry out common activities involved in daily living, 90.4\% of patients were able to perform the activities of daily living despite certain difficulties, and $2.8 \%$ of respondents performed limited self-care activities (both professional and nonprofessional). According to the AIMS and NHP scales, physical activity and joint pain were most strongly correlated with the four clinical measurements of disease activity, but the quality of life in the area of social interaction was not significantly associated with any clinical measures in any of the scales. Some studies have indicated that the influence of the radiological damage on the quality of life was less severe compared to pain, depression, disease activity and functional status [27, 28].

Borstlap et al. [29] analysed quality of life in terms of traditional clinical and laboratory determinants. The following scales were used to evaluate the quality of life of patients with RA: the Modified Health Assessment Questionnaire (MHAQ) and the Influence of Rheumatic Diseases on Health and Lifestyle (IRGL) scale. The clinical and laboratory variables were: hand muscle strength (measured by the vigour meter) and joint tenderness (assessed by the Ritchie Articu- 
lar Index and the Thompson Index to measure the symptoms of morning stiffness, walking time and the concentration of proteins in the acute phase). Correlations between traditional clinical variables and the areas of quality of life in the IRGL scale were observed. The symptoms of morning stiffness and walking time were strongly correlated with quality of life in physical functioning, physical activity and self-care. Joint pain, tenderness, swelling of joints and morning stiffness symptoms were strongly correlated with the IRG scale of pain. A weak correlation between clinical and laboratory variables and quality of life in the psychological and social aspects was found. Only the level of depression was strongly correlated with the quoted variables. The correlations presented above were higher compared with the results of Bijlsma et al. [30]. According to the results of the Kumar et al. [31] study, quality of life in RA patients following 12 weeks of treatment with disease-modifying anti-rheumatic drugs (DMARDs) improved, but it had no correlation with the serum levels of anti-CarP antibodies.

Recent studies in rheumatology concern qualitative research in assessing the quality of life of patients treated with biological drugs [32].

According to the results of a meta-analysis, the impact RA is substantial in both physical and mental domains, RA patients should be periodically assessed for the impact of their disease on their lives, and access to a multidisciplinary team is essential for the assessment and management of these aspects of their condition [33, 34].

In conclusion, in analysing the quality of life of patients with RA with regard to socio-demographic factors, disease duration, selected therapeutic methods and clinical variables, the following conclusions have been drawn:

- A good assessment of quality of life among RA patients depended on the support received from family and friends. A poor assessment of the quality of life of RA patients was due to their limited ability to perform the basic activities of life. This was associated with joint pain and walking and bending.

- The quality of life of RA patients depended on the gender of the respondents. Women scored lower in the emotional aspects than men. The age of the respondents influenced the assessment of the quality of life of RA patients. Young patients scored higher in the physical component. Quality of life in the affect component was scored higher in patients with rheumatoid arthritis and with secondary-level and university-level education.

- The assessment of quality of life in patients with rheumatoid arthritis in most of the subscales correlated with their hand muscle strength, a symptom of morning stiffness and joint pain intensity.
- Pain, Morning Stiffness and Grip Strength all seem to be risk factors of a poor quality of life among ambulatory patients with RA. Our findings suggest that community rehabilitation might significantly reduce such symptoms as pain, grip strength, and morning stiffness, and, at the same time, improve the quality of life of patients with RA.

- The study results may be helpful for further health-related studies on quality of life among RA studies and in making therapeutic decisions concerning quality of life improvement. In our studies we have not evaluated the quality of life of patients treated with biological drugs; therefore, future research should be conducted among these patients.

\section{Conflict of interest}

The authors declare no conflict of interest.

\section{References}

1. Whalley D, McKenna SP, de Jong Z, van der Heijde D. Quality of life in rheumatoid arthritis. Br J Rheumatol 1997; 36: 884-8.

2. Eberhardt K, Larsson BM, Nived K, Lindqvist E. Work disability in rheumatoid arthritis - development over 15 years and evaluation of predictive factors over time. J Rheumatol 2007; 34: 481-7.

3. Tłustochowicz W, Samborski W. The position of the Group of Experts for the National Consultant. Rheumatology the diagnosis and treatment of rheumatoid arthritis. Reumatologia 2008; 46: 111-4.

4. WHQOOL Group. The World Health Organization Quality of Life Assessment (WHOQOL). Position paper from the World Health Organization. Soc Sci Med 1995; 41: 1403-9.

5. Schipper H, Clnich J, Powell V. Quality of life studies: definitions and conceptual issues. In: Quality of Life and Pharmacoeconomics in Clinical Trials. Spilker B (ed.) Lippinocott-Raven, Philadelphia, 1996; 11-24.

6. Lawton PM. A multidimensional view of quality of life in frail elders: In: The Concept and Measurement of Quality of Life in the Frail Elderly. JE Birren JE, Lubben JE, Rowe JC, Deurhman DE (eds.), Academic Press Inc, New York 1991.

7. Ferrans CE, Powers MJ. Psychometric assessment of the quality of life index. Res Nur Health 1992; 15: 29-38.

8. Bowling A. Measuring Disease: Review of Disease Specific Quality of Life Measurement Scales. Open University Press, Buckingham, Philadelphia, 1995; 210-33.

9. Hill J, Bird H, Lawton C, Wright V. The Arthritis Impact Measurement Scales: an anglicized version to assess the outcome of British patients with rheumatoid arthritis. Br J Rheumatol 1990; 29: 193-6.

10. Abello-Banfi M, Cardie MH. Quality of life in rheumatoid arthritis: validation of a Spanish version at the Arthritis Impact Measurement Scales (Spanish-AIMS). J Rheumatol 1994; 21: 1250-5.

11. Archenholtz B, Bjelle A. Reliability, validity and sensitivity of a Swedish version of the revised and expanded Arthritis Impact Measurement Scales (AIMS-2). J Rheumatol 1997; 24: 1370-7. 
12. Baczyk G. The evaluation of the functioning and of the quality of life of patients with rheumatoid arthritis. Annales Academiae Medicae Bialostocensis 2005; 50 Suppl. 1: 170-17.

13. Arnett FC, Edworthy SM, Bloch DA, et al. The American Rheumatism Association 1987 revised criteria for the classification of rheumatoid arthritis. Arthritis Rheum 1988; 31: 315-24.

14. Aletaha D, Neogi T, Silman AJ, et al. Rheumatoid Arthritis Classification Criteria. An American College of Rheumatology/European League Against Rheumatism Collaborative Initiative. Arthritis Rheum 2010; 62: 2569-81.

15. Meenan R, Mason J, Anderson J, et al. AIMS-2: The content and properties of a revised and expanded arthritis impact measurement scales health status questionnaire. Arthritis Rheum 1992; 35: 1-10.

16. Bączyk G, Kleka P, Ochmańska M. Evaluation of psychometric Polish version of the Arthritis Impact Measurement Scales-2 (AIMS-2) in patients with rheumatoid arthritis. Reumatologia 2009; 47: 282-9.

17. Huskisson EC. Measurement of pain. Lancet 1974; 2: 1127-31.

18. Ritchie D, Bouyle J, McInnes J, et al. Clinical studies with an articular index for the assessment of joint tenderness in patients with rheumatoid arthritis. Q J Med 1968; 37: 393-406.

19. Steinbrocker O, Traeger C, Batterman R. Therapeutic criteria in rheumatoid arthritis. Am J Med Assoc 1949; 140: 659-61.

20. Bączyk G, Samborski P, Pieścikowska J, Kmieciak M. Comparison functioning and quality of life of patients with osteoarthritis and rheumatoid arthritis. Adv Med Sci 2007; 52 suppl. 1: 55-9.

21. Sierakowska M, Matys A, Kosior A, et al. Evaluation of quality of life in patients with rheumatoid arthritis. Reumatologia 2006; 44: 298-30.

22. Pincus T, Callahan LF. Association of low formal education level and poor health status - behavioral, in addition to demographic and medical explanations? J Clin Epidemiol 1994; 47: 355-61.

23. Gamal RM, Mahran SA, Fetoh NAE, Janbi F. Quality of life assessment in Egyptian rheumatoid arthritis patients: relation to clinical features and disease activity. Egypt Rheumatol 2016; 38: 65-70.

24. Haroon N, Aggarwal A, Lawrence A, Agarwal V, Misra R. Impact of rheumatoid arthritis on quality of life. Mod Rheumatol 2007; 17: 290-5.

25. Nordenskiold U, Grimby G. Assessments of disability in women with rheumatoid arthritis in relation to grip force and pain. Disabil Rehabil 1997; 19: 13-9.

26. Fitzpatrick R. The measurement of health status and quality of life in rheumatological disorders. Baill Clin Rheum 1993; 7: 207-317.

27. Rupp I, Boshuizen HC, Dinant HJ, Jacobi CE, van den Bos GA. Disability and health-related quality of life among patients with rheumatoid arthritis: association with radiographic joint damage, disease activity, pain, and depressive symptoms. Scand J Rheumatol 2006; 35: 175-81.

28. Sariyildiz MA, Batmaz I, Bozkurt M, et al. Sleep quality in rheumatoid arthritis: relationship between the disease severity, depression, functional status and the quality of life. J Clin Med Res 2014; 6: 44-52.

29. Borstlap M, van de Laar M, Zant J, van der Korst J. Components of health: an analysis in rheumatoid arthritis using quality of life questionnaires and clinical and laboratory variables. Ann Rheum Dis 1993; 52: 650-4.
30. Bijlsma JW, Huiskes CJ, Kraaimaat FW, Vanderveen MJ, Huber-Bruning O. Relation between patients' own health assessment and clinical and laboratory findings in rheumatoid arthritis. J Rheumatol 1991; 18: 650-3.

31. Kumar S, Pangtey G, Gupta R, Rehan HS, Gupta LK. Assessment of anti-CarP antibodies, disease activity and quality of life in rheumatoid arthritis patient on conventional and biological disease-modifying antirheumatic drugs. Reumatologia 2017; 55: 4-9.

32. Marshall NJ, Wilson G, Lapworth K, Kay LJ. Patients' perception of treatment with anti-TNF therapy for rheumatoid arthritis: a qualitative study. Rheumatology 2004; 43: 1034-8.

33. Matcham F, Rayner L, Hutton J, Monk A, Steel C, Hotopf M. Self-help interventions for symptoms of depression, anxiety and psychological distress in patients with physical illnesses: a systematic review and meta-analysis. Clin Psychol Rev 2014; 34: 141-57.

34. Matcham F, Scott I, Rayner L, et al. The impact of rheumatoid arthritis on quality of life assessed using the SF-36: a systematic review and meta-analysis. Semi Arthritis Rheum 2014; 44: 123-30. 